\title{
Gelisp 1.0: A Graphical interface for OpenMusic
}

\author{
Mauricio Toro \\ Universidad EAFIT
}

January 5, 2019

\section{Introduction}

Process calculi have been applied to the modeling of interactive music systems (27; 23, 28, 22, 34 , 25, 26, 21, 24, 20, 33, 39; 19; 38; 1, 35, 29, 5; 17, 14, 16, 18, 2, 32, 15, 30, 31, 13) and ecological systems $(36,7,37,8)$. In addition, research on algorithms (6, 4, 11; 9, 10) and software engineering (12, 3) also contributes to this field.

\section{Special Boxes}

\section{$2.1 \quad$ OMCSP Box}

This box is used to define a CSP and its heuristics.

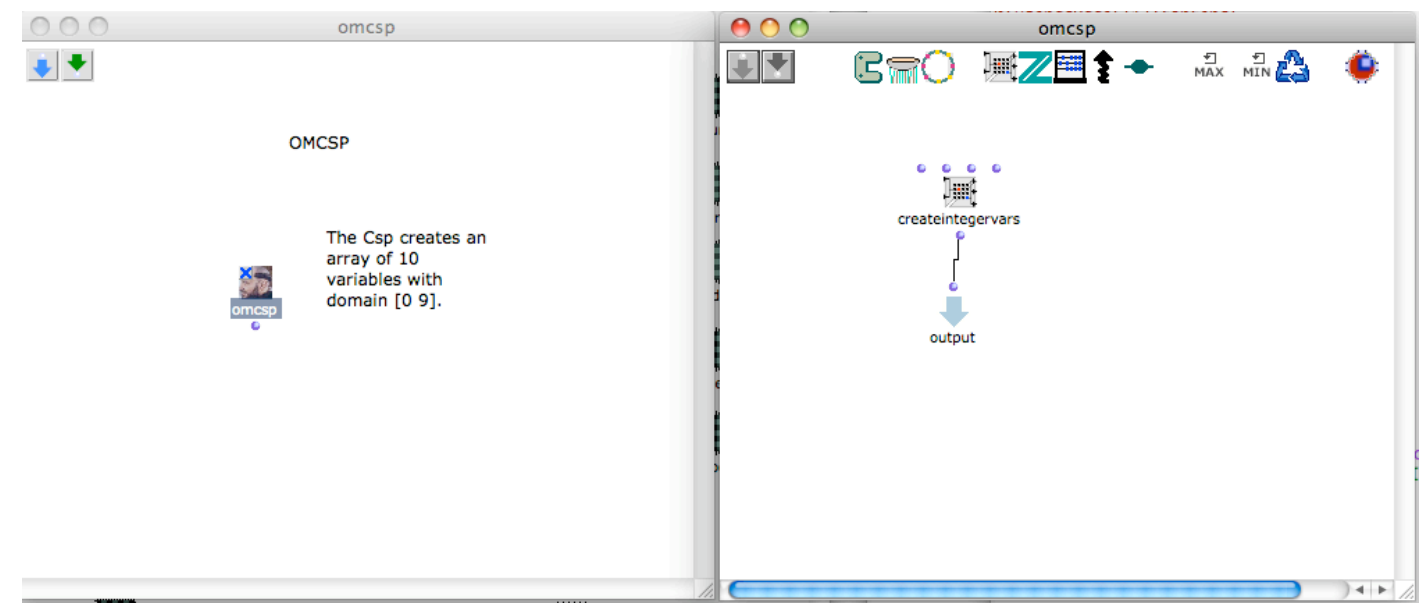

Figure 1: OMCsp Box

\subsection{Output Box}

This box is used to define the variables to observe in a CSP.

\subsection{Optimal-criterion Box}

This box is used to define the variable corresponding to the optimal-criterion in the search (optional).

\subsection{Create-interger-vars Box}

This box is used to define a list of finite domain variables. 


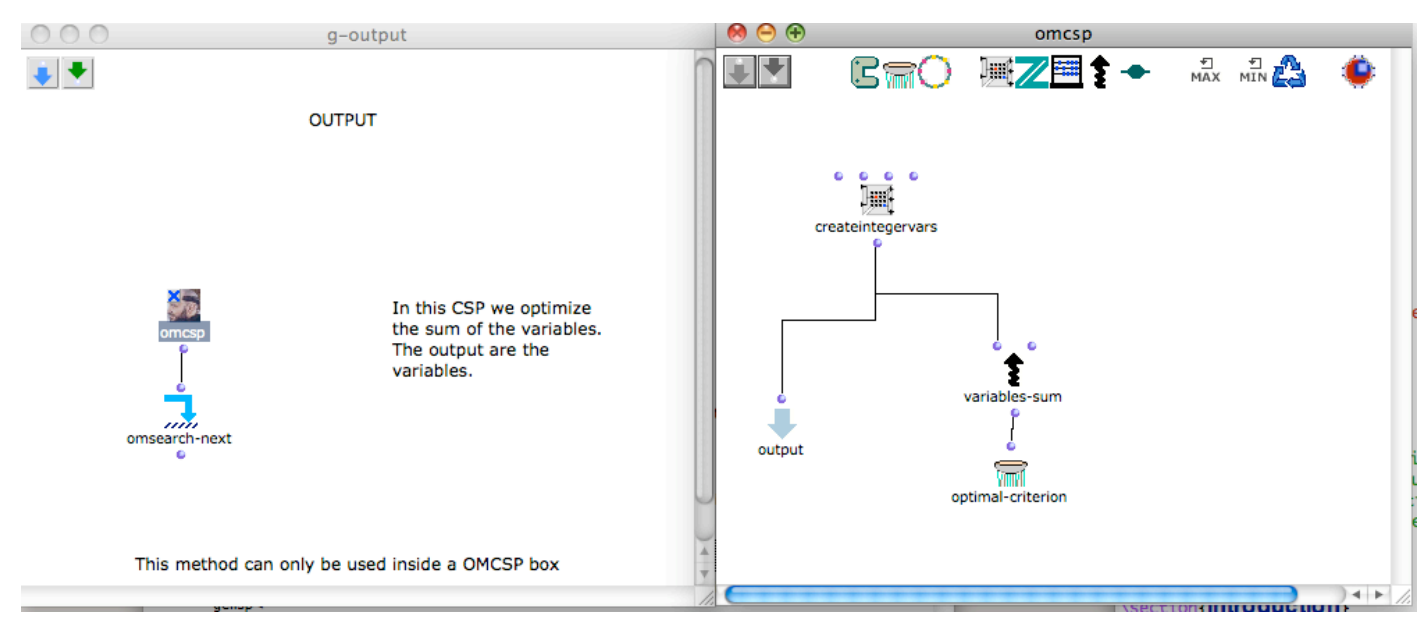

Figure 2: Output Box

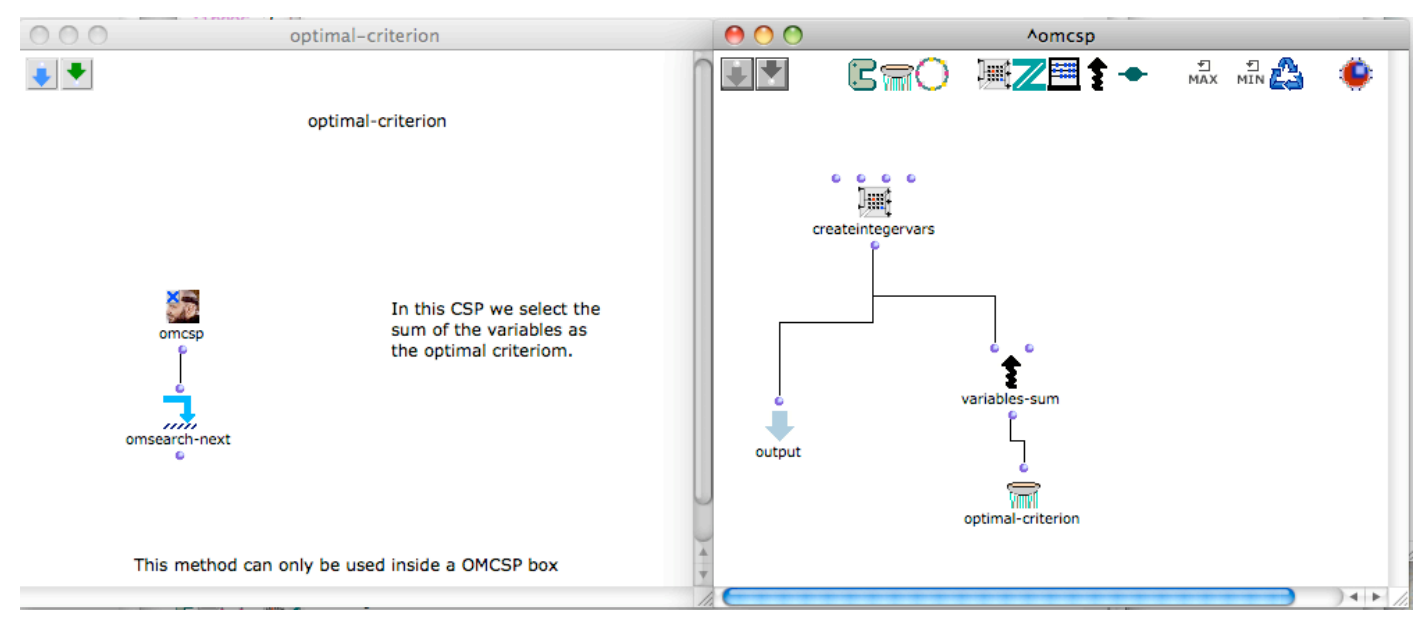

Figure 3: Optimal-criterion Box

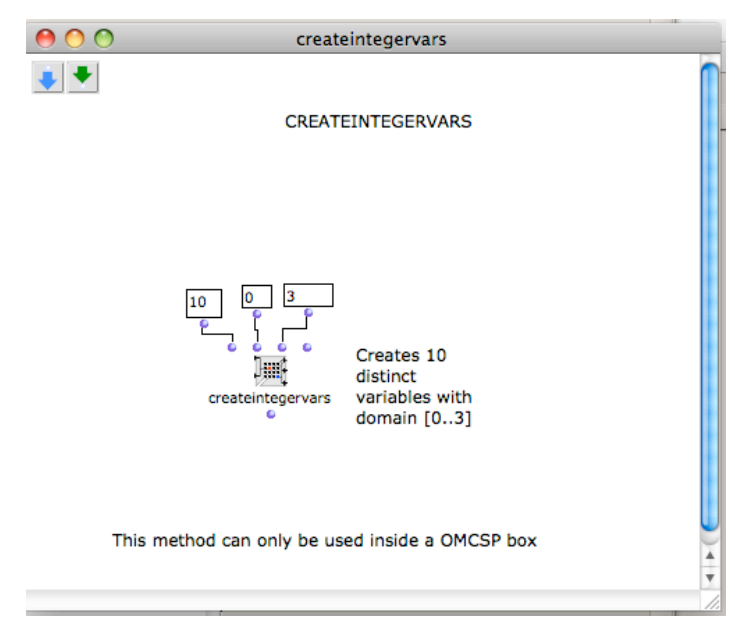

Figure 4: Create-interger-vars Box 


\subsection{Constraint Box}

This box is used to connect each constraint box in the patch.

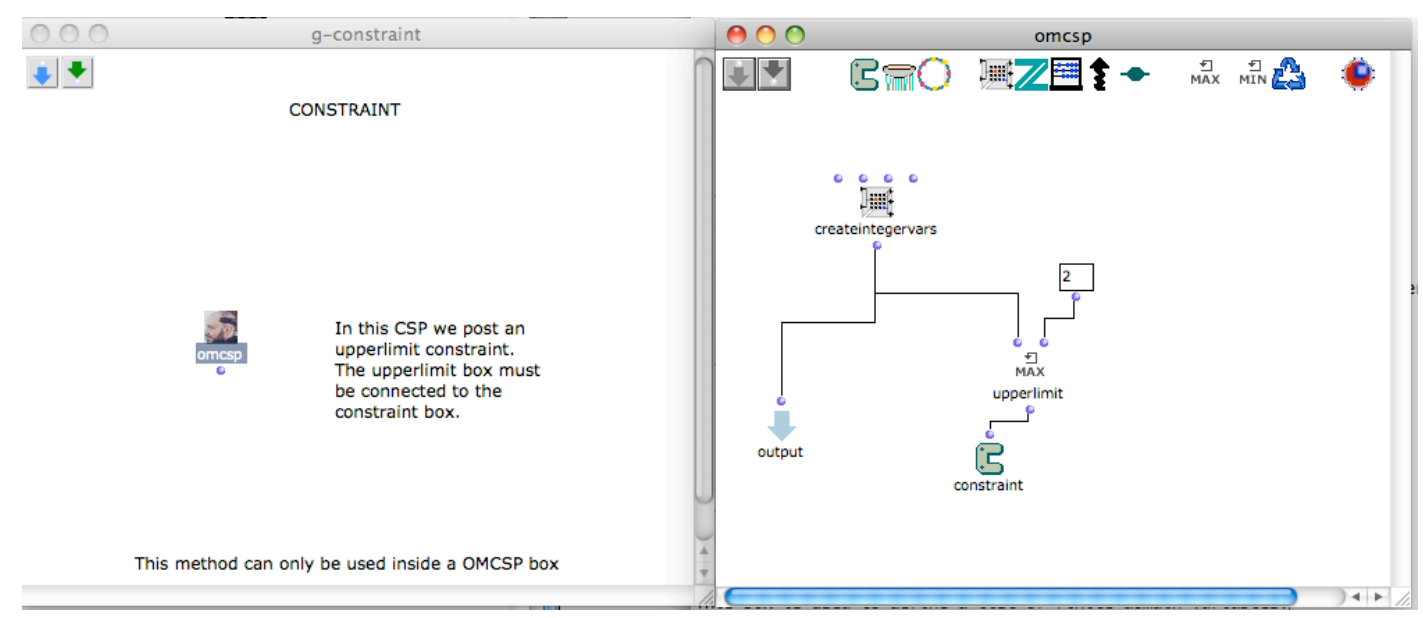

Figure 5: Constraint Box

\subsection{Timelimit Box}

Using this box we can setup a time limit for the search.

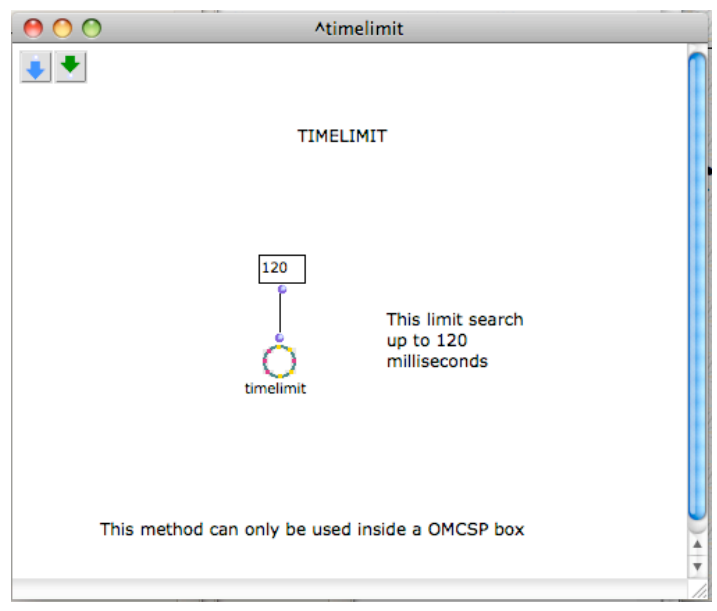

Figure 6: Timelimit Box

\subsection{Constraint Box}

This box is used to connect each constraint box in the patch.

\section{Constraint Boxes}

\section{1 forall $x_{i}+n_{i} \neq x_{j}+n_{j}$ Box}

This is a variation of the all-distinct constraint. 


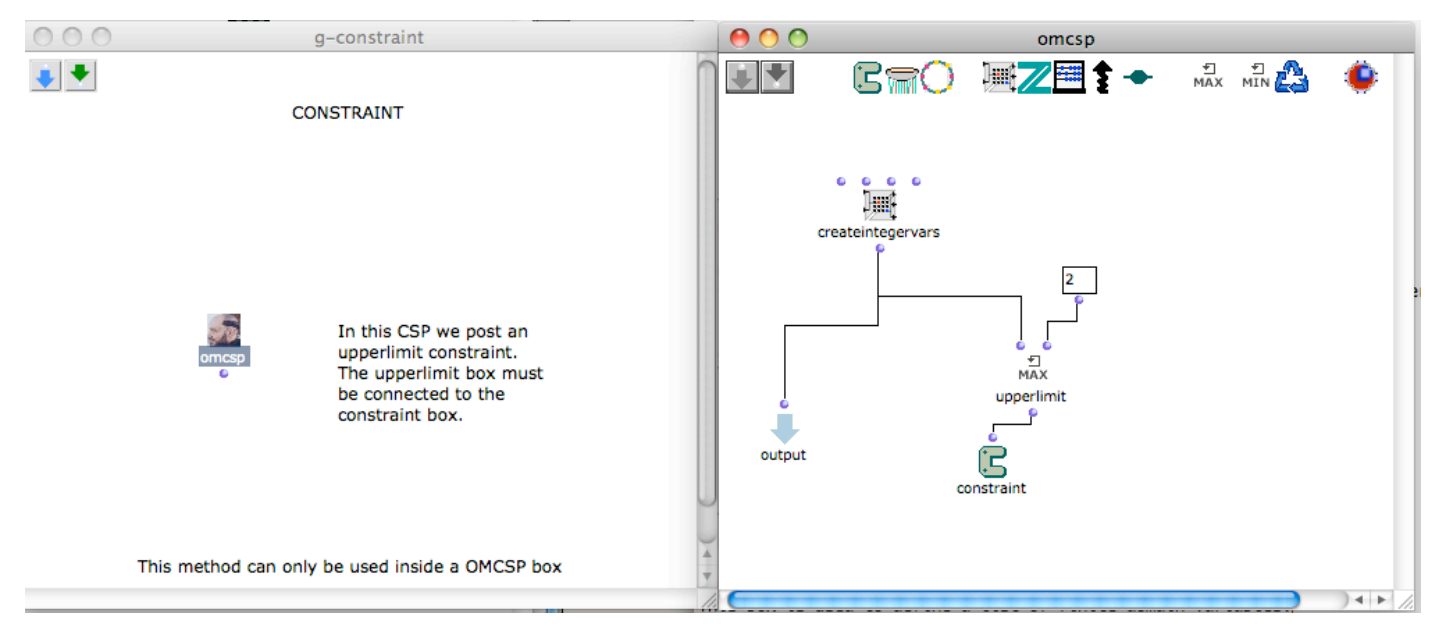

Figure 7: Constraint Box

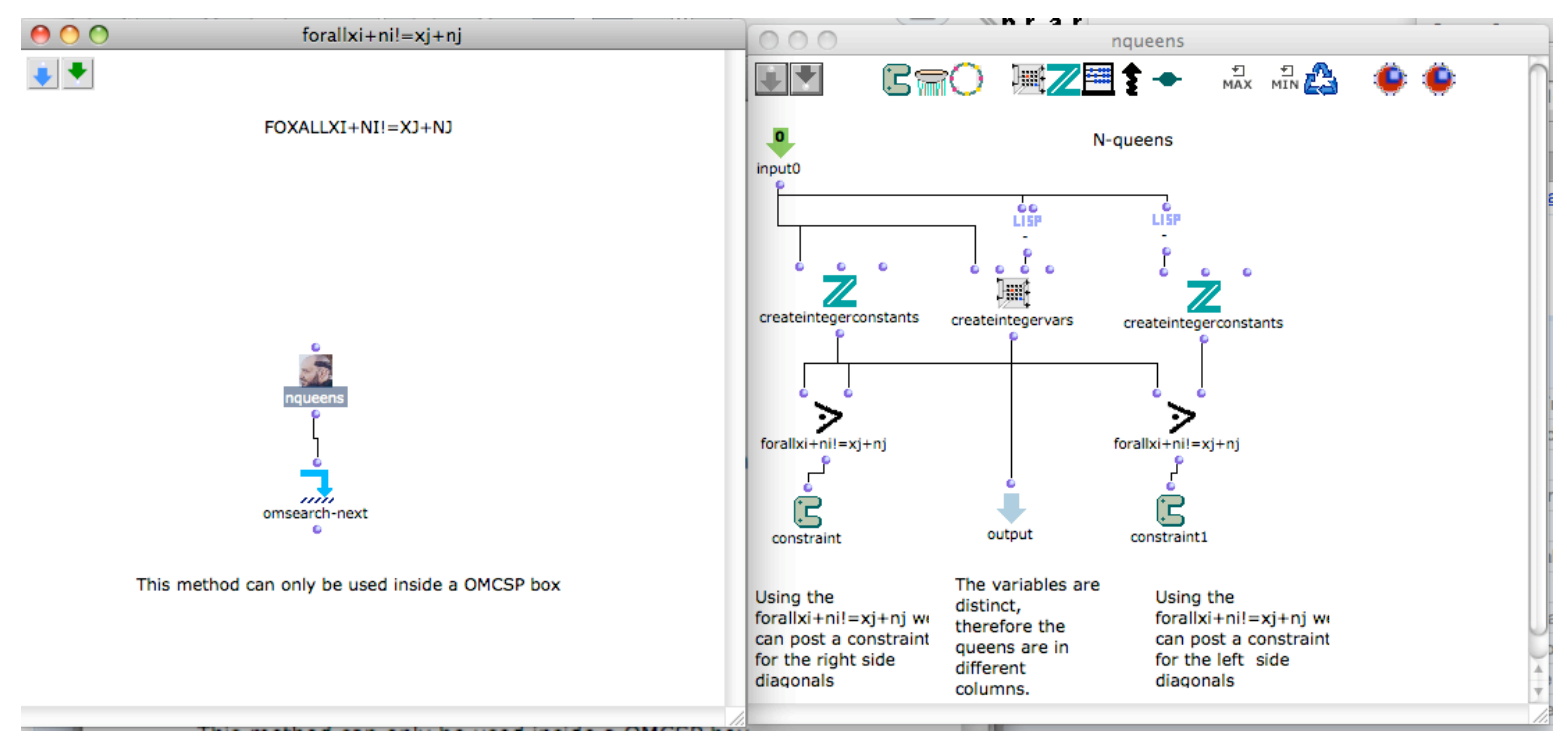

Figure 8: forall $x_{i}+n_{i} \neq x_{j}+n_{j}$ Box

\subsection{Motives-occurs $=,<=,>,>=$ Box}

These methods are used to post a constraint about the occurrences of each element in a list of motives in a list of variables.

\subsection{Geliss $=,<=,>,>=$ Box}

These methods are used to post a relational constraint about a finite domain variable (e.g., $a=2$ ) or two fd variables (e.g., $a<b)$.

\subsection{Memberof Box}

\section{Search Boxes}

\subsection{Omsearch-next Box}

This method search the next solution. If you want to find different solutions, block the omcsp box. 


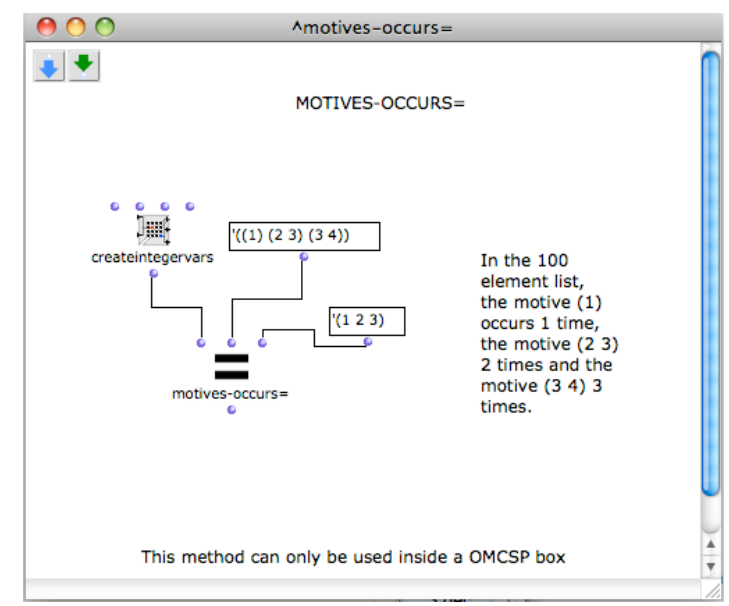

Figure 9: Motives-occurs $=,<=,>,>=$ Boxes

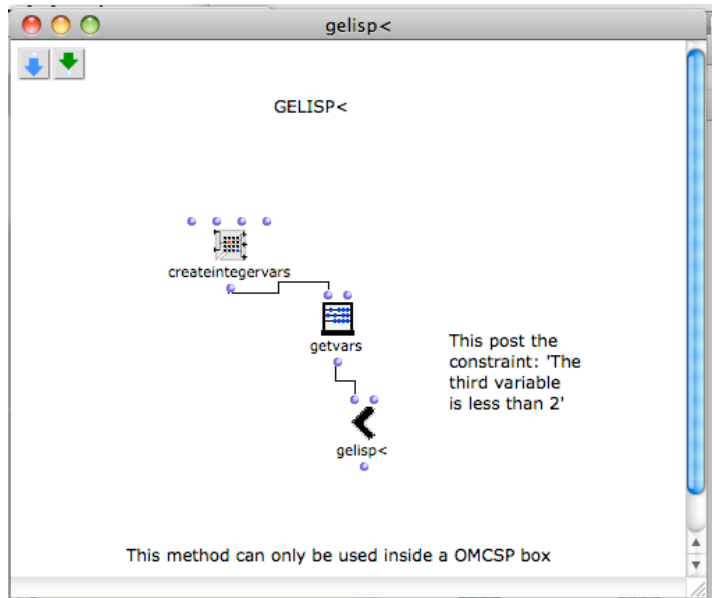

Figure 10: Gelisp $=,<=,>,>=$ Boxes

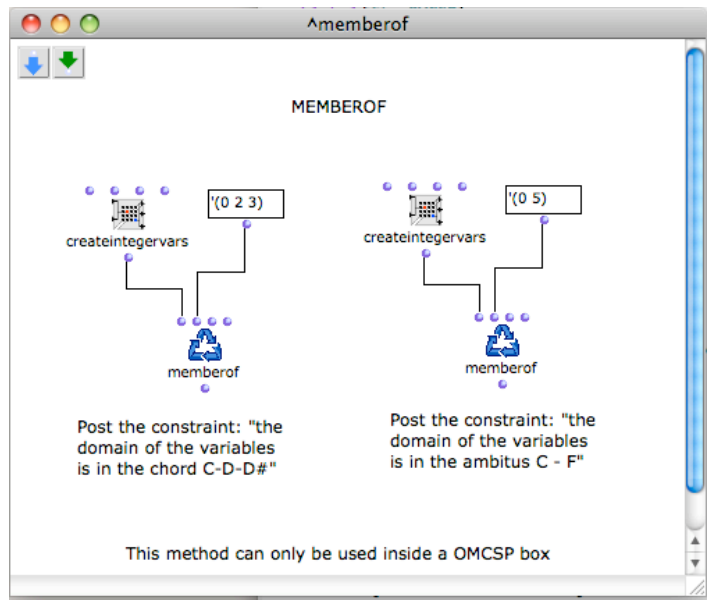

Figure 11: Memberof Box 


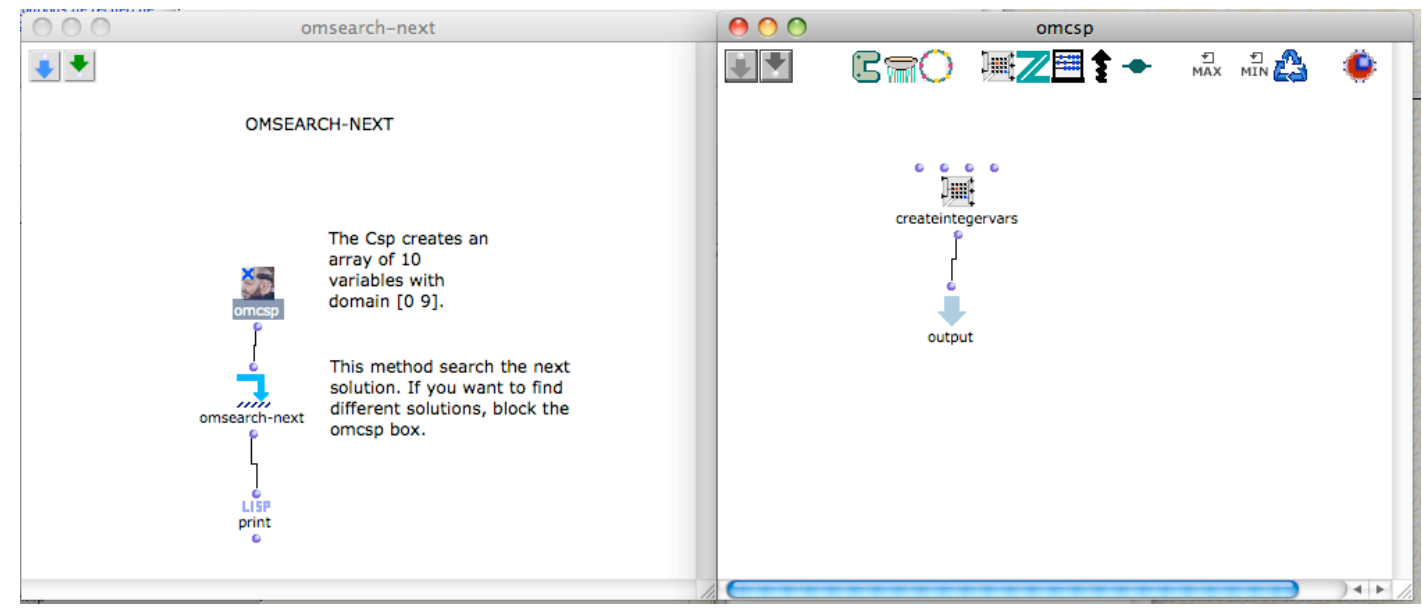

Figure 12: om-search-next Box

\subsection{Omsearch-all Box}

This method search the all the solutions.

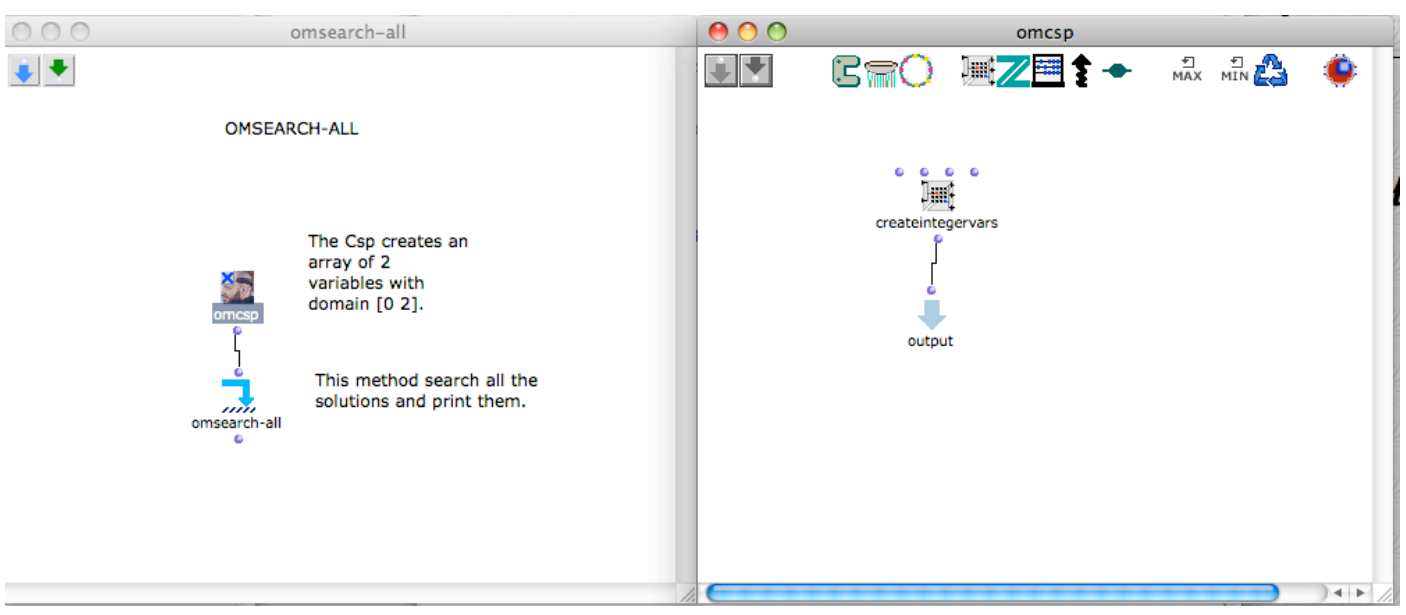

Figure 13: om-search-next Box

\section{References}

[1] Allombert, A., Desainte-Catherine, M., And Toro, M. Modeling temporal constrains for a system of interactive score. In Constraint Programming in Music, G. Assayag and C. Truchet, Eds. Wiley, 2011, ch. 1, pp. 1-23.

[2] Aranda, J., Assayag, G., Olarte, C., Pérez, J. A., Rueda, C., Toro, M., and Valencia, F. D. An overview of FORCES: an INRIA project on declarative formalisms for emergent systems. In Logic Programming, 25th International Conference, ICLP 2009, Pasadena, CA, USA, July 14-17, 2009. Proceedings (2009), P. M. Hill and D. S. Warren, Eds., vol. 5649 of Lecture Notes in Computer Science, Springer, pp. 509-513.

[3] Mazo, R., Toro, M., And Cobaleda, L. Definicion de la arquitectura de referencia de un dominio: de la elucidacion al modelado. In Guia para la adopcion industrial de lineas de productos de software, R. Mazo, Ed. Editorial Eafit, 2018, pp. 193-210.

[4] Moreno, J. D. A., Passos, S., And Toro, M. On-line assembling mitochondrial DNA from de novo transcriptome. CoRR abs/1706.02828 (2017). 
[5] Olarte, C., Rueda, C., Sarria, G., Toro, M., and Valencia, F. Concurrent Constraints Models of Music Interaction. In Constraint Programming in Music, G. Assayag and C. Truchet, Eds. Wiley, Hoboken, NJ, USA., 2011, ch. 6, pp. 133-153.

[6] Patiño-Forero, C., Agudelo-Toro, M., and Toro, M. Planning system for deliveries in Medellín. ArXiv e-prints (Nov. 2016).

[7] Philippou, A., and Toro, M. Process Ordering in a Process Calculus for Spatially-Explicit Ecological Models. In Proceedings of MOKMASD'13 (2013), LNCS 8368, Springer, pp. 345-361.

[8] Philippou, A., Toro, M., and Antonaki, M. Simulation and Verification for a Process Calculus for Spatially-Explicit Ecological Models. Scientific Annals of Computer Science 23, 1 (2013), 119-167.

[9] Quintero, E., Sanchez, M., Roldan, N., And Toro, M. Genetic algorithm for optimal distribution in cities. ArXiv e-prints (Nov. 2018).

[10] Rendon, C., Hernández, J. L., Ruiz-Salguedo, O., Álvarez, C. A., and Toro, M. Wing Profile Evolution driven by Computational Fluid Dynamics. In Tecnologías Avanzadas de Mecatrónica, Diseño y Manufactura: Memorias Cuarto Congreso AMDM (2018), Editorial Universidad Autónoma de Manizales, pp. 345-347.

[11] Restrepo, J. M. C., Palacio, A. F. Z., And Toro, M. Assembling sequences of DNA using an on-line algorithm based on debruijn graphs. CoRR abs/1705.05105 (2017).

[12] Suescún, E., Toro, M., Mazo, R., Velasquez, D., Vallejo, P., Cardona, J. F., Rincón, R., Werneck, V. M., And do Prado Leite, J. C. C. SimulES-W: A Collaborative Game to Improve Software Engineering Teaching. Computación y Sistemas 22, 3 (2018), 953-983.

[13] Toro, M. Exploring the possibilities and limitations of concurrent programming for multimedia interaction and graphical representations to solve musical csp's. Tech. Rep. 2008-3, Ircam, Paris.(FRANCE), 2008.

[14] Toro, M. Probabilistic Extension to the Factor Oracle Model for Music Improvisation. Master's thesis, Pontificia Universidad Javeriana Cali, Colombia, 2009.

[15] Toro, M. Towards a correct and efficient implementation of simulation and verification tools for probabilistic ntcc. Tech. rep., Pontificia Universidad Javeriana, May 2009.

[16] Toro, M. Structured interactive musical scores. In Technical Communications of the 26th International Conference on Logic Programming, ICLP 2010, July 16-19, 2010, Edinburgh, Scotland, UK (2010), M. V. Hermenegildo and T. Schaub, Eds., vol. 7 of LIPIcs, Schloss Dagstuhl - Leibniz-Zentrum fuer Informatik, pp. 300-302.

[17] Toro, M. Structured Interactive Scores: From a simple structural description of a multimedia scenario to a real-time capable implementation with formal semantics. PhD thesis, Univeristé de Bordeaux 1, France, 2012.

[18] Toro, M. Structured interactive music scores. CoRR abs/1508.05559 (2015).

[19] Toro, M. Probabilistic Extension to the Concurrent Constraint Factor Oracle Model for Music Improvisation. ArXiv e-prints (Feb. 2016).

[20] Toro, M. Probabilistic Extension to the Concurrent Constraint Factor Oracle Model for Music Improvisation . Inteligencia Artificial 57, 19 (2016), 37-73.

[21] Toro, M. Backtracking-free interactive music scores with temporal relations over rythms. OSF Preprints 10.31219/osf.io/bwzsk (Oct 2018).

[22] Toro, M. Combining temporal relations and signal processing into interactive scores. OSF Preprints osf.io/sqmer (Oct 2018).

[23] Toro, M. Current Trends and Future Research Directions for Interactive Music. ArXiv e-prints (Oct. 2018).

[24] Toro, M. CURRENT TRENDS AND FUTURE RESEARCH DIRECTIONS FOR INTERACTIVE MUSIC. Journal of Theoretical and Applied Information Technology 69, 16 (2018), 5569-5606.

[25] Toro, M. Modeling michael jarrell's csp in gelisp. OSF Preprints osf.io/2ebzj (Oct 2018).

[26] Toro, M. ntccmc: A bounded-time model checker for ntcc. OSF Preprints osf.io/c8kah (Oct 2018).

[27] Toro, M. Towards a correct and efficient implementation of simulation and verification tools for probabilistic ntcc. ArXiv e-prints (Oct. 2018).

[28] Toro, M. Towards a correct and efficient implementation of simulation and verification tools for probabilistic ntcc. OSF Preprints 10.31219/osf.io/3wp5z (Oct 2018).

[29] Toro, M., Agón, C., Assayag, G., And Rueda, C. Ntccrt: A concurrent constraint framework for real-time interaction. In Proc. of ICMC'09 (Montreal, Canada, 2009).

[30] Toro, M., and Desainte-Catherine, M. Concurrent constraint conditional branching interactive scores. In Proc. of SMC '10 (Barcelona, Spain, 2010).

[31] Toro, M., Desainte-Catherine, M., and Baltazar, P. A model for interactive scores with temporal constraints and conditional branching. In Proc. of Journées d'Informatique Musical (JIM) '10 (May 2010). 
[32] Toro, M., Desainte-Catherine, M., and Castet, J. An extension of interactive scores for multimedia scenarios with temporal relations for micro and macro controls. In Proc. of Sound and Music Computing (SMC) '12 (Copenhagen, Denmark, July 2012).

[33] TORO, M., DESAINTE-CATHERINE, M., And CASTET, J. An extension of interactive scores for multimedia scenarios with temporal relations for micro and macro controls. European Journal of Scientific Research 137, 4 (2016), 396-409.

[34] Toro, M., Desainte-Catherine, M., Janin, D., And Orlarey, Y. Real-time interactive streams and temporal objects language. OSF Preprints 10.31219/osf.io/a6stk (Oct 2018).

[35] Toro, M., Desainte-Catherine, M., and Rueda, C. Formal semantics for interactive music scores: a framework to design, specify properties and execute interactive scenarios. Journal of Mathematics and Music 8, 1 (2014), 93-112.

[36] Toro, M., Philippou, A., Arboleda, S., Puerta, M., and Vélez S., C. M. Mean-field semantics for a process calculus for spatially-explicit ecological models. In Proceedings of the Eleventh International Workshop on Developments in Computational Models, Cali, Colombia, October 28, 2015 (2016), C. A. Muñoz and J. A. Pérez, Eds., vol. 204 of Electronic Proceedings in Theoretical Computer Science, Open Publishing Association, pp. 79-94.

[37] Toro, M., Philippou, A., Kassara, C., And Sfenthourakis, S. Synchronous parallel composition in a process calculus for ecological models. In Proceedings of the 11th International Colloquium on Theoretical Aspects of Computing - ICTAC 2014, Bucharest, Romania, September 17-19 (2014), G. Ciobanu and D. Méry, Eds., vol. 8687 of Lecture Notes in Computer Science, Springer, pp. 424-441.

[38] TORO, M., RUEDA, C., AGÓN, C., AND ASSAYAG, G. Ntccrt: A concurrent constraint framework for soft real-time music interaction. Journal of Theoretical \&s Applied Information Technology 82, 1 (2015).

[39] TORO, M., RUEDA, C., AGÓN, C., And ASSAYAG, G. Gelisp: A framework to represent musical constraint satisfaction problems and search strategies. Journal of Theoretical $\&$ Applied Information Technology 86, 2 (2016). 